\title{
Factors affecting nurse interns' compliance with standard precautions for preventing stick injury
}

\author{
Shereen R. Dorgahm, Heba K. Obied * \\ Faculty of Nursing, Tanta University, Tanta , Egypt
}

Received: March 1, 2016

Accepted: June 26, 2016

Online Published: August 9, 2016

DOI: $10.5430 /$ jnep.v6n12p121

URL: http://dx.doi.org/10.5430/jnep.v6n12p121

\begin{abstract}
Aim: Compliance with standard precautions (SPs) is a critical workplace safety issue for nurse interns (NIs) as they are clinically incompetent, and obligated to cover nursing shortage in intensive care units (ICUs). Thus current study aimed to assess factors affecting NIs' compliance with SPs.

Methods: Descriptive study design was used. The sample included 110 NIs trained in ICUs at University Hospitals. Tools: Tool (I) Factors affecting NIs' compliance with SPs included items on compliance with SPs, environmental risk factors, stick injuries, and vaccination, influence of role-modeling and refreshment program on compliance with SPs. Tool (II) Knowledge test covered SPs and transmission of blood-borne pathogens.

Results: About $40 \%$ of NIs noncompliance with SPs due to lack in supplies and equipments, Majority of them had low and moderate knowledge level regarding SPs. $71.8 \%$ had 4-6 times needle stick injuries and 88.2\% didn't report it. 39.1\% never use protective equipment in emergency and $29.1 \%$ always recap contaminated needles.

Conclusions: NIs are at risk of stick injury as they lacking knowledge and skills regarding SPs. Moreover, lacking of supplies and training programs regarding SPs, and absence of reporting system of these incidents contribute to NIs noncompliance with SPs thus they are more at risk of blood transmitted diseases.
\end{abstract}

Key Words: Standard precautions, Nurse interns, Compliance, Stick injury

\section{INTRODUCTION}

Nurse interns (NIs) are newly graduated nursing students, require to be trained and supervised by experienced nurses through different intensive care units (ICUs) to function independently and competently. ${ }^{[1]}$ NIs should spend an internship year in teaching hospitals, but those hospitals face serious shortage and cost reduction issues, thus NIs are obligated to function as professional nurses, while they still lacking skills and experience. ${ }^{[2,3]}$ Ensuring NIs competency and safety is crucial as they are considered the future nursing staff. Different studies revealed that considerable percent of newly graduated nurses lacking knowledge and skills regarding stan- dard precautions (SPs).$^{[1,4-6]}$ Additionally, previous studies reported that NIs experienced needle stick injury (NSI), thus they are more prone to blood transmitted diseases, while they have to keep patient safety and follow SPs to protect self and patients. ${ }^{[7,8]}$

NSI is a serious occupational hazard facing healthcare workers (HCWs) including NIs worldwide. It was estimated that annually about 69,000 NSIs in Canada, in USA up to $1,000,000$ and in UK 100,000; about half of these injuries go unreported. NSIs lead to about $66,000 \mathrm{HBV}, 16,000 \mathrm{HCV}$ and 1,000 HIV infections among HCWs worldwide; mostly in developing countries. Furthermore, NSIs can transmit

${ }^{*}$ Correspondence: Heba K. Obied; Email: hebaobied@yahoo.com; Address: Faculty of Nursing, Tanta University, Tanta, Egypt. 
other diseases such as malaria, tuberculosis, diphtheria and herpes. ${ }^{[7-11]}$ Center for Disease Control (CDC, 1996) declared about "standard precautions" that must be followed by HCWs to limit the risk of transmitting blood-borne and other pathogens. ${ }^{[12,13]}$ SPs encompass hand washing, using of personal protective equipment PPE (e.g., gloves, gowns, etc.), safe practices (handling sharps and contaminated equipments), safe discarding of sharps and medical wastes, and sterilization of surgical instruments. Following these measures have crucial affects on the safety of both patients and HCWs, but unfortunately, despite the simplicity and clarity of these measures, compliance level with standard precaution among nurses and NIs is still low. ${ }^{[14,15]}$

Compliance is the level of precision and constancy in following prescribed standard protocols to achieve the desired outcomes. ${ }^{[16]}$ Various factors can influence the level of compliance including cultural, economical and social factors. Adding to that, the level of individual's self-efficacy and knowledge can affect their level of compliance. Different studies revealed that following standard precautions reduced the exposure risk of blood and body fluids. Furthermore, they proved that compliance with standard precautions correlates with nurses' perception of risk, type of training received, their level of practice, and the nature of work setting. ${ }^{[17-20]}$

Studies revealed that ICUs, emergency rooms and medicalsurgical units have the highest rates of needle stick injuries, where nurse interns spend their internship year. ${ }^{[1,17,21]}$ Reasons behind nurses' noncompliance with standard precautions may include personal habits, carelessness, discomfort with PPE shortage of time, staff and supplies. Inadequate reporting system, absence of staff safety policies and management disregard of nurses' safety are additional factors hinder nurses compliance with standard precautions. ${ }^{[17,22]}$ Moreover inappropriate practices by health care givers such as needle recapping, and use PPE according to patient diagnosis make nurse interns' more at risk as they imitate those models. ${ }^{[8,22]}$ So it is vital to explore factors affect nurse interns' compliance with standard precautions to enable healthcare managers to design more effective strategies to raise their compliance and keep their future staff safe and well protected.

\subsection{Aim of the study}

The current study aimed to assess factors affecting nurse interns' compliance with standard precautions for preventing stick injury.

\subsection{Research questions}

The current study had two main questions:

- What are the factors affecting nurse interns' compli- ance with standard precautions?

- Are nurse interns' having the compliance with standard precautions?

- Do nurse interns' compliance with standard precautions?

\section{MATERIALS \& METHOD}

\subsection{Design}

A descriptive cross-sectional research design was used in the current study.

\subsection{Setting}

The current study was conducted at University Hospital ICUs, included medical, anesthetic, neurological, neonatal, pediatric, and cardiac ICUs.

\subsection{Sample}

The participants (110) nurse interns who were willing to participate in the study. The inclusion criteria include all NIs male and female graduated from Faculty of Nursing, and spend their internship year at the previously mentioned setting. The participant NIs fill in the study tools (selfadministered questionnaire and knowledge test) in the presence of the researchers during their work shifts.

\subsection{Tools}

Two tools were used in the current study, modified by researchers based on Logan CA (2002). ${ }^{[17]}$ Tool (I) self administered questionnaire "Factors affecting nurse interns' compliance with standard precautions" consisted of 2 parts. Part I: sample characteristics, included age, gender, general performance appraisal, and currently enrolled in. Part II: composed of four sections with (48 items) 1st section: compliance with standard precautions (9 items) encompassed wearing PPEs, disposal of sharps, and recapping needles. 2nd section: influence of role-modeling on NIs level of compliance with SPs (7 items) contained suggesting the use of PPE for others and following the actions of professional persons they admire, Scoring system for these sections 3 points Likert Scale always, sometimes, and never. 3rd section: environmental risk factors (23 items) included availability of PPE, hospital safety measures, and supporting policies. Scoring system 3 points Likert Scale yes, no, and do not know. 4th section: included closed end questions encompassed reasons for non-compliance with SPs (1 ques), frequency of needle stick injuries and reporting it (2 ques), and receive HBV vaccination (1 ques), emphasis on preventing needle stick in relation to other occupational hazards (1 ques) and receiving orientation program on SPs (4 ques). Tool (II) Nurse interns' knowledge test consisted of 20 MCQs covered SPs and transmission of blood-borne pathogens. 


\subsection{Method}

The tools were introduced to a jury of 5 experts to test its validity. A pilot study was conducted on 11 (10\%) of NIs to assess the tools' applicability and reliability and those interns were excluded from the main study sample. The Cronbach's value was 0.80 and the Content Validity Index was $91 \%$.

\subsection{Ethical considerations}

After the approval of hospital authorities, the purpose of the study was explained to the study subject and informed consents were obtained from them. The participants were ensured about the confidentiality of their data, and the right to withdraw was confirmed. NIs consumed about 20 minutes to fill in the study tools. The data was collected within three month since October to December 2014.

\subsection{Statistical analysis}

The study data was collected, tabulated and subjected to statistical analysis by SPSS (version 17), also Microsoft office Excel was used for data handling and graphical presentation. Quantitative variables are described by the Mean, and Standard Deviation (SD). Qualitative categorical variables are described by proportions and Percentages.

\section{Results}

Table 1 shows demographic characteristics for participant nurse interns. It demonstrates that about two thirds $(60.9 \%)$ of NIS aged $\leq 21$ years old, with mean age $(21.4 \pm 0.73)$. Majority (87.3\%) of participant nurse interns were females. Regarding general performance appraisal more than half (55.5\%) had very good. An equal percent (18.2\%) of the participants currently enrolled in anesthesia, neurological and cardiology ICUs, as well, $23.6 \%$ enrolled in medical ICU, and $21.8 \%$ enrolled in pediatric ICU.
Table 1. Demographic characteristics of participant nurse interns $(n=110)$

\begin{tabular}{lll}
\hline \multirow{2}{*}{ Items } & \multicolumn{2}{l}{ Nurse Interns } \\
\cline { 2 - 3 } & No. & $\%$ \\
\hline Age (years) & 67 & 60.9 \\
$\leq 21$ & 43 & 39.1 \\
$>21$ & & \\
Mean \pm SD 21.4 \pm 0.73 & & \\
Gender & 14 & 12.7 \\
Male & 96 & 87.3 \\
Female & & \\
General Performance Appraisal(GPA) & 19 & 17.3 \\
Excellent & 61 & 55.5 \\
Very Good & 22 & 20.0 \\
Good & 8 & 7.3 \\
Satisfactory & & \\
Currently enrolled in & 20 & 18.2 \\
Anesthesia ICU & 20 & 18.2 \\
Neurological ICU & 20 & 18.2 \\
Cardio ICU & 26 & 23.6 \\
Medical ICU & 24 & 21.8 \\
Pediatric ICU & & \\
\hline
\end{tabular}

Figure 1 shows perception of participant nurse interns regarding compliance with standard precautions. In relation to the emphasis on preventing transmission of needle stick blood borne pathogens, high percent $(71.8 \%)$ of the studied sample perceived it is the most important aspect, and $12.7 \%$ viewed it has the same level of importance as other occupational safety aspects. Regarding the reasons for noncompliance with standard precautions two fifth (40\%) of the sample recorded lack of supplies and equipment, around one third $(29.1 \%)$ of them forgot to use, and $23.6 \%$ viewed compliance with standard precautions as time consuming. Concerning the nurse interns' knowledge regarding standard precautions, majority ( $70 \%$ and $22.7 \%$ ) of the studied nurse interns had moderate and low knowledge level respectively.

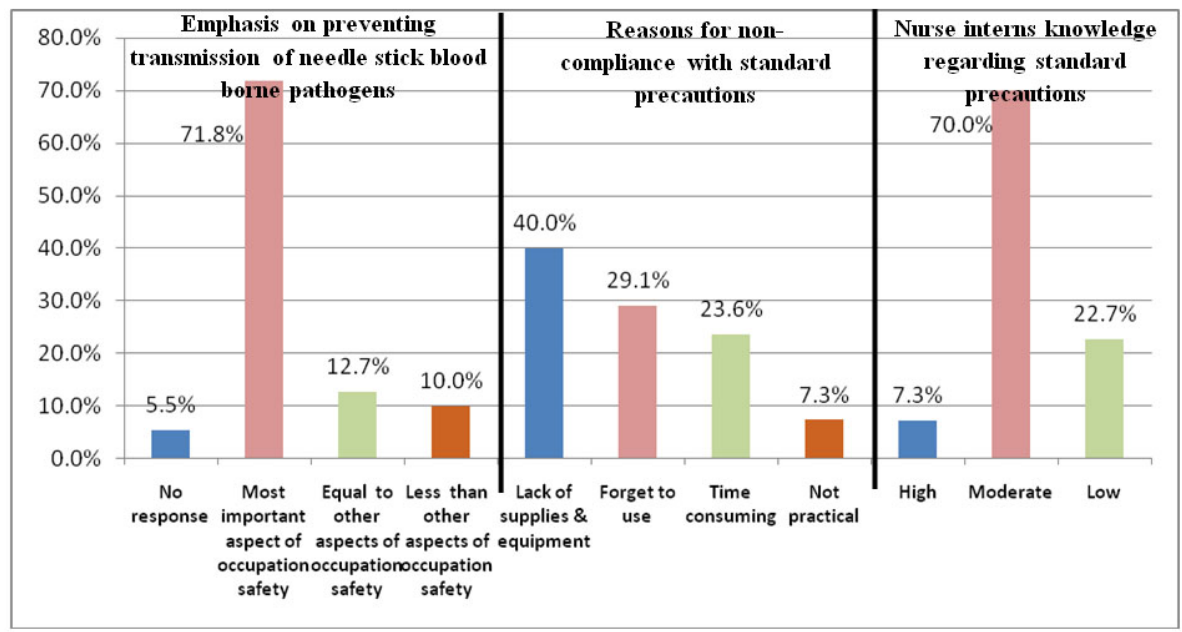

Figure 1. Perception of participant nurse interns regarding compliance with standard precautions 
Figure 2 shows the frequency of NSI, reporting NSI and receive HBV vaccination among participant nurse interns. It can be noticed that the highest percentage $(71.8 \%)$ had 4-6 times needle stick injuries during last six months, followed by $12.7 \%$ had $1-3$ times, and $5.5 \%$ had more than 6 times. Majority $(88.2 \%)$ of nurse interns didn't report needle stick injuries, while only $11.8 \%$ reported needle stick injuries. Around two thirds (61.8\%) of the studied sample didn't receive hepatitis B virus vaccination.

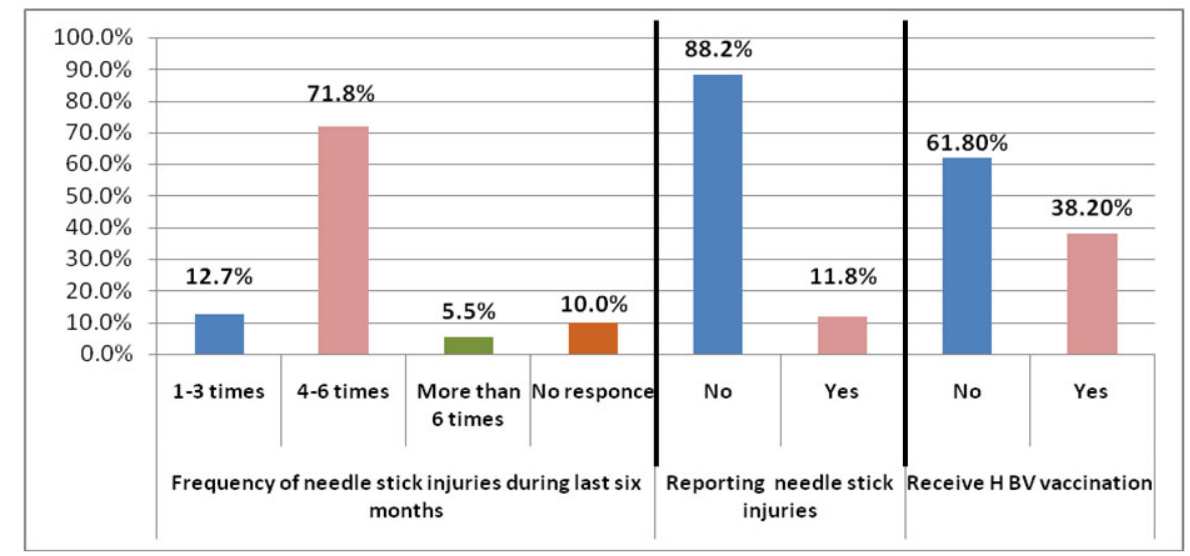

Figure 2. Frequency of NSI, reporting NSI and receive HBV vaccination among participant nurse interns

Table 2 shows compliance with standard precautions among participant nurse interns. It can be noticed that more than half $(59.1 \%)$ of participants always wear gloves to draw blood samples, and $66.4 \%$ always use designated containers to dispose sharps. Moreover, two fifths (40\%) sometimes use one-handed recapping technique, followed by $40 \%$ of them always use protective equipment in procedure depend on patient's condition, and $44.5 \%$ sometimes don't use PPE in emergency situations, as well $84.5 \%$ of them always and sometimes wear gloves for starting injections. On the other hand, all the participants never wear safety glasses when starting IV's, and $40.9 \%$ of them never recap contaminated needles.

Table 2. Compliance with standard precautions among participant nurse interns

\begin{tabular}{|c|c|c|c|c|c|c|}
\hline \multirow{2}{*}{ Compliance with standard precautions } & \multicolumn{2}{|c|}{ Never } & \multicolumn{2}{|c|}{ Sometimes } & \multicolumn{2}{|c|}{ Always } \\
\hline & No & $\%$ & No & $\%$ & No & $\%$ \\
\hline Wear gloves to draw blood samples. & 17 & 15.5 & 28 & 25.5 & 65 & 59.1 \\
\hline Use designated containers to dispose sharps. & 11 & 10.0 & 26 & 23.6 & 73 & 66.4 \\
\hline Use one-handed recapping technique. & 43 & 39.1 & 44 & 40.0 & 23 & 20.9 \\
\hline Using PPE depend on pt. condition. & 24 & 21.8 & 42 & 38.2 & 44 & 40.0 \\
\hline Use protective equipment in emergency situations. & 34 & 30.9 & 49 & 44.5 & 27 & 24.5 \\
\hline Wear gloves for starting injections. & 17 & 15.5 & 45 & 40.9 & 48 & 43.6 \\
\hline Prefer using traditional needle than needle less system. & 32 & 29.1 & 50 & 45.5 & 28 & 25.5 \\
\hline Wear safety glasses when starting IV's. & 110 & 100.0 & 0 & 0.0 & 0 & 0.0 \\
\hline Recap contaminated needles. & 45 & 40.9 & 33 & 30.0 & 32 & 29.1 \\
\hline
\end{tabular}

Table 3 shows perception of environmental risk factors among participant nurse interns. It demonstrates that all the participant nurse interns recorded the non-availability of the following soap supply, disposable hand-towels, airdryer, trash container near each sink, incineration apparatus of sharps in the unit, and isolation room in the unit. While, all of them recorded the availability of infectious waste sep- arated from household waste, gloves, and masks. All the studied sample did not receive any hospital training upon hiring, in addition around two thirds $(68.2 \%, 64.5 \%$ and $60.9 \%$ ) of the studied sample recorded non availability of the following no cost $\mathrm{HB}$ vaccination to all hospital employees, needle stick injuries zero tolerance policy, and post-exposure, follow-up and prophylaxis respectively. 
Table 3. Perception of environmental risk factors among participant nurse interns

\begin{tabular}{|c|c|c|c|c|c|c|}
\hline \multirow{2}{*}{ Observations of Environmental Risk Factors } & \multicolumn{2}{|l|}{ Yes } & \multicolumn{2}{|l|}{ No } & \multicolumn{2}{|c|}{ Do not Know } \\
\hline & No. & $\%$ & No. & $\%$ & No & $\%$ \\
\hline Presence of a sink in each patients care room & 33 & 30.0 & 77 & 70.0 & 0 & 0.0 \\
\hline Presence of soap supply & 0 & 0.0 & 110 & 100.0 & 0 & 0.0 \\
\hline Availability of disposable hand-towels & 0 & 0.0 & 110 & 100.0 & 0 & 0.0 \\
\hline Availability of air-dryer & 0 & 0.0 & 110 & 100.0 & 0 & 0.0 \\
\hline Presence of trash container near each sink & 0 & 0.0 & 110 & 100.0 & 0 & 0.0 \\
\hline Availability of alcoholic hand rubs & 44 & 40.0 & 66 & 60.0 & 0 & 0.0 \\
\hline Presence of safety container for sharps in each room & 110 & 100.0 & 0 & 0.0 & 0 & 0.0 \\
\hline Presence of incineration apparatus for sharps in the unit & 0 & 0.0 & 110 & 100.0 & 0 & 0.0 \\
\hline Availability of an isolation room in the unit & 0 & 0.0 & 110 & 100.0 & 0 & 0.0 \\
\hline Infectious waste separated from household waste & 110 & 100.0 & 0 & 0.0 & 0 & 0.0 \\
\hline Presence of containers with lids for general waste & 58 & 52.7 & 52 & 47.3 & 0 & 0.0 \\
\hline \multicolumn{7}{|l|}{ Availability of personal protective equipment (PPE) } \\
\hline Is there available gloves? & 110 & 100.0 & 0 & 0.0 & 0 & 0.0 \\
\hline Is there available masks? & 110 & 100.0 & 0 & 0.0 & 0 & 0.0 \\
\hline Is there available disposable aprons? & 0 & 0.0 & 79 & 71.8 & 31 & 28.2 \\
\hline Is there available goggles? & 0 & 0.0 & 79 & 71.8 & 31 & 28.2 \\
\hline Is there available face shields? & 0 & 0.0 & 79 & 71.8 & 31 & 28.2 \\
\hline \multicolumn{7}{|l|}{ Hospital support role } \\
\hline Hospital provide training on infection prevention upon hire & 0 & 0.0 & 110 & 100.0 & 0 & 0.0 \\
\hline Availability of annual training on infection prevention & 7 & 6.4 & 61 & 55.5 & 42 & 38.2 \\
\hline Availability of log of sticks injuries\& other exposure events & 0 & 0.0 & 56 & 50.9 & 54 & 49.1 \\
\hline Availability of post-exposure follow-up \& prophylaxis & 0 & 0.0 & 67 & 60.9 & 43 & 39.1 \\
\hline Availability of no cost HB vaccination to hospital workers & 0 & 0.0 & 75 & 68.2 & 35 & 31.8 \\
\hline Importance of needle safety is stressed in all hospital units & 18 & 16.4 & 63 & 57.3 & 29 & 26.4 \\
\hline Presence of stick injuries zero tolerance policy in hospital & 9 & 8.2 & 71 & 64.5 & 30 & 27.3 \\
\hline
\end{tabular}

Table 4 shows influence of role-modeling on NIs' compli- and 38.2\% sometimes imitate the actions of preceptor they ance and advice others to use standard precautions. Around admire. In relation to advice others to use safety precautions, one fifth $(18.2 \%, 20 \%)$ of nurse interns mentioned that staff more than fifty percent $(54.5 \%$ and $50 \%)$ of the participants nurses as well as their preceptor never follow needle safety sometimes advice another NI, and staff nurse to follow stanprecautions respectively. More than one third (40\%) of them dard precautions. While, $73.6 \%$ of them never advice a sometimes imitate the actions of staff nurses they admire, preceptor who is not following safety precautions.

Table 4. Influence of role-modeling on NIs' compliance and advice others to use standard precautions

\begin{tabular}{|c|c|c|c|c|c|c|}
\hline \multirow{2}{*}{$\begin{array}{l}\text { Influence of role-modeling on NIs' compliance } \\
\text { with SPs }\end{array}$} & \multicolumn{2}{|c|}{ Never } & \multicolumn{2}{|c|}{ Sometimes } & \multicolumn{2}{|c|}{ Always } \\
\hline & No & $\%$ & No & $\%$ & No & $\%$ \\
\hline Imitate the actions of preceptor you admire & 40 & 36.4 & 42 & 38.2 & 28 & 25.5 \\
\hline Imitate the actions of staff nurses you admire & 43 & 39.1 & 44 & 40.0 & 23 & 20.9 \\
\hline Preceptor follow needle safety precautions & 22 & 20.0 & 38 & 34.5 & 50 & 45.5 \\
\hline Staff nurses follow needle safety precautions & 20 & 18.2 & 39 & 35.5 & 51 & 46.4 \\
\hline \multicolumn{7}{|l|}{ Advice others } \\
\hline Another NI who is not using precautions & 24 & 21.8 & 60 & 54.5 & 26 & 23.6 \\
\hline Staff nurse who is not using proper precautions & 25 & 22.7 & 56 & 50.9 & 28 & 25.5 \\
\hline Preceptor who is not using proper precautions & 81 & 73.6 & 29 & 26.4 & 0 & 0.0 \\
\hline
\end{tabular}

Figure 3 shows methods of teaching used in orientation pro- the second method of teaching used in the orientation program regarding standard precautions. More than half $(56.4 \%$ and $53.6 \%$ ) of participant nurse interns recorded that lecture was the main method and videotaped presentation was gram regarding standard precautions respectively. Majority (90.9\%) of them viewed that videotaped presentation as the most helpful method used in the orientation program. Fig- 
ure 4 illustrates timing, provider and number of interns in orientation program regarding standard precautions. All the studied sample had the standard precautions orientation program at the beginning of internship year, by faculty staff, and in groups contain from (51 up to 100) nurse interns.

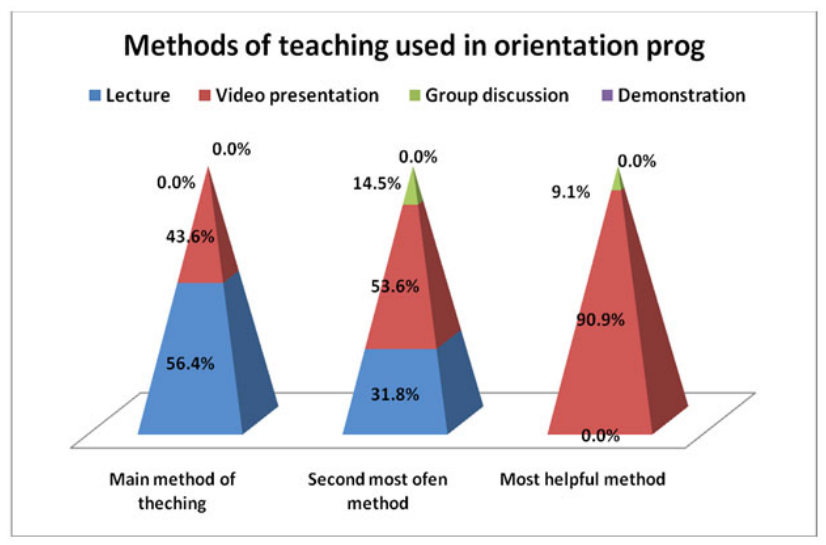

Figure 3. Methods of teaching used in orientation program regarding standard precautions

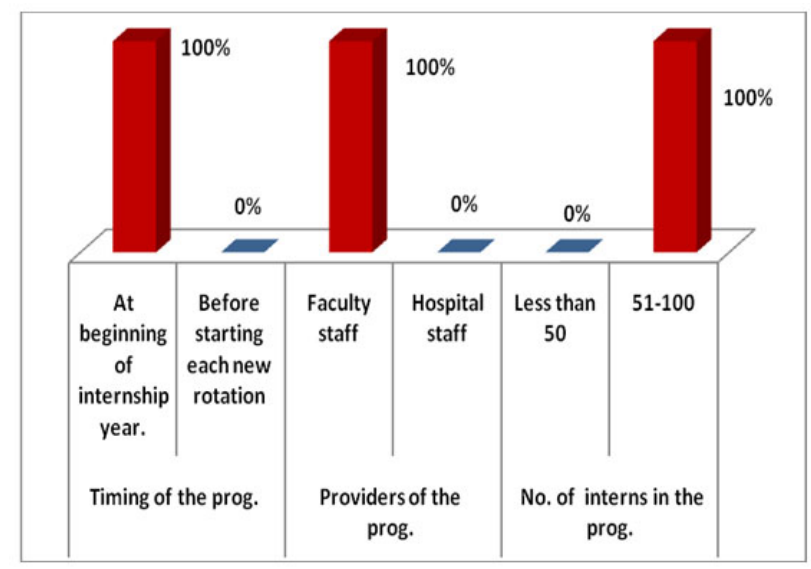

Figure 4. Timing, provider and No. of interns in orientation program regarding standard precautions

\section{Discussion}

Today healthcare organizations suffer from severe nursing shortage especially teaching hospitals, so they depend on nurse interns to cover this shortage. Based on this, it is crucial to ensure compliance of NIs with standard precautions to protect themselves as well as patients. Findings of the present study revealed that the highest percentage of the studied NIs recorded that preventing needle stick injuries is the most important occupational safety aspect. This result may be attributed to those NIs work in ICUs with critically ill patients thus they are more at risk for NSIs and its subsequent transmission of blood-borne diseases especially hepatitis $C$ virus $(\mathrm{HCV})$ as it is a major public health problem in Egypt. ${ }^{[23]}$
Thus HCWs safety should be ensured and translated in the hospital policies and actions.

This result is in accordance with Elder and Paterson (2006), ${ }^{[24]}$ they reported that needle stick injuries have negative consequences in health care delivery especially in developing countries, where the qualified healthcare workers are limited with respect to the disease burden in the population. In this respect Beghdadli et al. (2008), ${ }^{[25]}$ Sreedharan et al. (2011), ${ }^{[4]}$ Pruss-Ustun et al. (2003) ${ }^{[26]}$ and Ramos-Gomez et al. (1997) ${ }^{[27]}$ mentioned that health care givers are at risk of exposure to blood borne infections from sharp injuries and contact with body fluids. Also the world health report (2002), ${ }^{[28]}$ announced that needle-stick injuries lead to the highest prevalence of HIV, HBV and HCV among healthcare providers worldwide. Accordingly, it is vital to avoid stick injuries to prevent exposure to blood borne diseases.

The present study results demonstrated that studied subjects recorded the reasons for non-compliance with standard precautions were lack in supplies and equipment, forgot to use PPE, and using PPE was time consuming. This may be due to excessive work overload results from inappropriate nurse/patient ratio, and limited resources of teaching hospitals as these hospitals provide services for a wide range of clients semi-free and its budget derived from governmental bodies. Adding to that the stressful environment of ICUs where NIs work and lack of hospital rules and regulations that protect health care workers from exposure. Moreover our results illustrated that majority of study sample had low and moderate knowledge level regarding standard precautions, while majority of them had excellent and very good GPA. This can be justified as those NIs during their final year of undergraduate nursing program trained to apply administrative skills and to carry out primary prevention in community care settings. Additionally they did not receive orientation programs at the beginning of each rotation to refresh their knowledge because of nursing shortage and limited in-service educational opportunities. Thus those NIs require refreshment and orientation programs regarding infection control, SPs and other main procedures prior internship year.

These findings are in accordance with many studies that focused on the factors that lead to non-compliance with standard precautions. Oliveira et al. (2010), ${ }^{[29]}$ Sax et al. (2005), ${ }^{[30]}$ Stein et al. (2003), ${ }^{[31]}$ and Osborne $(2003)^{[32]}$ recorded that noncompliance with standard precautions related to lack of knowledge, supplies, equipments, and time. Also they found that forgetfulness, being uncomfortable with using PPE, interference with carrying out procedures, and distance from PPE or facility lead to non-compliance with 
SP. Jawaid et al. (2009) ${ }^{[12]}$ listed five factors to improve compliance level including availability of equipment, time, ability to remind to comply, applicability, and sufficient knowledge about standard precautions, isolation technique and proper waste disposal. Therefore, it is important to instill in NIs good infection control practices through education and supervised practice from the very beginning, before incorrect practice develops into a habit and increase their awareness of PPE to avoid exposure to blood borne pathogens.

Additionally, study by Amoran and Onwube (2013) ${ }^{[33]}$ revealed that majority of respondents reported that non availability of the equipments was a major reason for noncompliance to standard precautions. However, Oliveria et al. (2009), ${ }^{[34]}$ Lopez et al. $(2006)^{[35]}$ and Sreedharan (2011) ${ }^{[4]}$ observed that knowledge level had serious effect on healthcare providers' level of compliance regarding standard precautions. However, knowledge on the transmission of blood borne disease in health care facilities is very limited and unsafe practices are common.

Concerning frequency of needle stick injuries, reporting stick injuries and receive hepatitis B virus vaccination, the present study indicated that high percent of nurse interns had 4-6 times needle stick injuries during last six months and majority of them didn't report needle stick injuries. More over around two thirds of present study subjects didn't receive HBV vaccination. These findings may be due to lack of preceptorship program and inappropriate ratio between preceptors /interns, where preceptors have high workload to provide patient care beside their roles to supervise and guide interns. Additionally, those preceptors did not receive adequate training to carry out their role. Therefore, collaboration and cooperation is required between the Nursing faculty and hospital administrative bodies to overcome this problem. Also no clear reporting system or even post injury policy is announced for both staff and interns.

NIs require frequent guidance and restrict supervision especially during the first three months, where their practical skills are being shaped. Adding to that, the hospital policies for preventing stick injuries must be clearly stressed and implanted on those novice nurses as they will be the hospital future staff. These findings are confirmed with CDC $(2004)^{[36]}$ declaration that needle-stick injuries considered the major risk among HCWs. Also they specified six types of sharps lead to stick injuries including hypodermic needles, suture needles, butterfly, scalpel blades, IV catheter and phlebotomy needles. Also Hashmi et al. (2012) $)^{[37]}$ and Singru and Banerjee (2008) ${ }^{[38]}$ showed that the highest incidence of occupational exposure was among nurses especially novice ones and only half of these incidents were reported.
Present study findings go in the same line with national survey conducted by CDC (2004) ${ }^{[36]}$ which declared that around a quarter of healthcare workers didn't receive any dose of hepatitis B vaccine and about one third never accomplished the full vaccine series. Therefore, hepatitis B vaccine must be available systematically for all HCWs as well as, protective procedures remains crucial in order to minimize the risk of occupational HBV infection.

Regarding studied nurse interns' compliance to occupational precautions, present study showed that more than half of them always wear gloves to draw blood samples, and around two thirds always use designated containers to dispose sharps. Around one third of them never use one-handed recapping technique, and never use protective equipment in emergency situations. Moreover, more than half of the studied NIs sometimes and always recap contaminated needles. These findings are in congruence with Siegel et al. (2007) ${ }^{[39]}$ who identify standard precautions as a practice meant to prevent transmission of infectious agents among HCWs through the use of suitable PPE, practice of hand hygiene, appropriate handling of sharp instruments, proper waste disposal and the practice of environmental cleaning using isolation techniques .

Results of the present study showed that although participants were compliance to protective equipment, all of them never wear safety glasses when starting IV's, this may be due to unavailability of these glasses in clinical settings. Furthermore, findings indicated that studied participants sometimes didn't use PPE in stressful \& hurried situations; this may be related to stock irregularity, unavailability of PPE, and feeling uncomfortable with PPE. Thus PPE must be available all the time and learn NIs that using PPE is a must and priority to protect self and patient even if they were uncomfortable to them. Earlier studies by Chan et al. (2002) $)^{[18]}$ and Jawaid et al. (2009) ${ }^{[12]}$ confirmed the present study findings as they found that use of PPE such as mask and goggles was not common among care givers. Also Luo et al. $(2010)^{[40]}$ reported that the use of personal protective equipments like eye shields, masks and quarantine cloths had the least compliance among Chinese nurses.

In relation to the observation of environmental risk factors, all the study subjects recorded that there were no soap supply, disposable hand-towels, air-dryer, trash container near sinks, incineration apparatus for sharps, isolation room in their units, or even receive training on infection control by the hospital upon their hiring. Furthermore, more than two thirds of them recorded that there were no available disposable aprons, goggles, face shields, or even no cost HB vaccination for hospital workers. This may be attributed to limited funds and old design of the hospital buildings as it was affiliated to 
University since 1960s. This required the government to reconsider the budgets allotted to teaching hospitals. Based on the present study findings around two thirds of the subjects follow the actions of preceptor and staff nurse they admire. Also they suggest the use of PPE to another nurse intern or staff nurse who is not using SPs. Those NIs are lacking experience as well as self confidence in their practical skills so require to work under the supervision of professional model till they gain professional self confidence. Therefore, it is important for hospitals to carefully select the suitable preceptors who train those NIs and act as a professional model to be followed. Jawaid et al. (2009) ${ }^{[12]}$ and Clement et al. $(2002)^{[41]}$ revealed that lacking of suitable modalities was the most important factor for noncompliance with standard precautions.

Our study revealed that more than half of participants recorded that lecture was the main method and videotaped presentation is the second method of teaching used in the orientation program. Majority of them noticed videotaped presentation as the most helpful method used in the program. All the studied sample had the orientation program at the beginning of internship year, by faculty staff, and in group contain from (51 up to 100) nurse intern. Stem from their sense of responsibility the faculty of nursing carryout orientation program for their graduates to overcome this gap in the university hospitals, but it seems to be still not sufficient. This program last for one week prior the internship year, where faculty staff provide quick revision on all the clinical and administrative skills required from NIs. The number of the students and the teaching methods required to be reconsidered also this program cannot substitute the orientation period at the beginning of each new clinical rotation for NIs. The present study findings were confirmed by Logan (2002) ${ }^{[17]}$ who revealed that the teaching strategies and the number of students in educational programs affect the students' ability to learn the desired skills and knowledge. Also the present study findings showed there were no statistical significant correlation between any of the NIs' demographic characteristics and their level of compliance with standard precautions even their general performance appraisal. This may be due to the entire sample have the same criteria. The findings of Chan et al. ${ }^{[18]}$ contradicted our results; they found that participants' ages and years of experience have significant positive relationship with hand washing compliance.

\section{Conclusion}

The present study concluded that nurse interns perceived needle stick injury as the most important aspect of occupational safety. NIs compliance or non can influenced by several factors including their insufficient knowledge and skills regarding standard precautions, and lacking of supplies and equipments. Moreover lack of hospital supporting policies that can be viewed in absence of staff awareness about reporting system or post stick injury procedures that negatively affect NIs compliance level with SPs. Also lacking of educational programs and hiring untrained nursing staff to carryout preceptor role can contribute to noncompliance with standard precautions.

Based on the findings of the current study, it is recommended to ensure the availability of supplies and equipment, establish continuous training and supervision programs for both nurse interns and other healthcare providers. Moreover, establish strict hospital "zero tolerance needle stick injury" policy, and efficient reporting system. Set up an appropriate surveillance technique at the hospital to ensure proper response and treatment of needle stick injury.

Furthermore, college should establish preceptorship program to prepare competent preceptors. College teaching staff and nurse administrators at hospital should use the results from the current study. Further research should be conducted by the college to assess undergraduate nurse students' compliance with standard precaution.

\section{ACKNOWLEDGEMENTS}

The researchers would like to thank College Dean, who gave us the opportunity to complete the project and always try to overcome any obstacles. We also gratefully thank all the participants associated with the research.

\section{CONFlicts OF INTEREST Disclosure}

The authors declare that there is no conflict of interest.

\section{REFERENCES}

[1] Obied H, Shabaan F, Shalaby H, et al. Application of Designed Orientation Program for Nurse Interns Based on Learning Needs Assessment. Journal of American Science. 2013; 9(3): 80-91.

[2] Chesnutt BM, Everhart B. Meeting the Needs of Graduate Nurses in Critical Care Orientation: Staged Orientation Program in Sur- gical Intensive Care. Critical Care Nurse. 2007; 27(3): 36-51. PMid:17522191

[3] Nayeri ND, Negarandeh R. Conflict among Iranian hospital nurses: a qualitative study. Human Resources for Health. 2009. Available from: http://www.human-resources-health.com/content/ $7 / 1 / 25$ 
[4] Sreedharan J, Muttappillymyalil J, Venkatramana M. Knowledge about standard precautions among university hospital nurses in the United Arab Emirates. EMHJ. 2011; 17(4): 331-334.

[5] Kaşlı M, İlban MO. The relationship between problems faced during internships and interns' view of profession and intention to work in the tourism industry. Eurasian Journal of Educational Research. 2013; 52: 79-96

[6] El Ashmawy E. Nurses' knowledge and performance about infection control standard precautions in Dialysis Units. Tanta University. Faculty of Nursing. Unpublished Master Thesis. 2012.

[7] Jaybhaye D, Dahire P, Nagaonkar A, et al. Needle Stick Injuries among Health Care Workers in Tertiary Care Hospital of ural India. International Journal of Medical Science and Public Health. 2014; 3(1): 49-52. http://dx.doi.org/10.5455/ijmsph.2013.230 920133

[8] Gupta D, Agrawal V, Gupta S, et al. Needle Stick Injuries among Health Care Worker. People's Journal of Scientific Research. 2015; 8(2): 17-22

[9] Muralidhar S, Singh P, Jain R, et al. Needle stick injuries among health care workers in a tertiary care hospital of India. Indian J Med Res. March 2010; 405-410. PMid:20418554

[10] RaisN, Jamil H. Prevalence of Needle Stick Injuries among Health Care Providers. International Journal of Endorsing Health Science Research. 2013; 1(2): 73-79.

[11] Ontario Ministry of Labour. Occupational Health \& Safety Branch. Handbook: Needlestick/Sharps Safety and Prevention.

[12] Jawaid M, Iqbal M, Shahbaz S. Compliance with Standard Precautions: A long way ahead. Iranian J Publ Health. 2009; 38(1): 85-88.

[13] Centres for Disease Control. Recommendations for isolation precautions in hospitals. (Part II) Hospital Infection Control Practices Advisory Committee. Am J Infect Control. 1996; 24: 32-52. PMid:8651518

[14] Labrague L, Rosales R, Tizon M. Knowledge of and Compliance with Standard Precautions among Student Nurses. International Journal of Advanced Nursing Studies. 2012; 1(2): 84-97. http://dx.doi.org/10.14419/ijans.v1i2.132

[15] Vaz1 K, McGrowder D, Alexander-Lindo R, et al. Knowledge, Awareness and Compliance with Universal Precautions among Health Care Workers at the University Hospital of the West Indies, Jamaica. International Journal of Occupational and Environmental Medicine. 2010; 4(1): 171-81.

[16] Thirumalai A. Nursing compliance with standard fall prevention protocol among acute care hospital nurses. UNLV Theses/Dissertations/Professional Papers/Capstones. 2010.

[17] Logan CA. Nursing Students' Knowledge, Observation of Environmental Risk Factors, and Compliance with Recommended Precautions for the Prevention of Transmission of Infectious Diseases by Needle Stick Injury. A Dissertation Submitted to the Graduate Faculty of the Louisiana State University and Agricultural and Mechanical College in partial fulfillment of the requirements for the degree of Doctor of Philosophy in The School of Human Resource Education and Workforce Development. 2002.

[18] Chan R, Alexander M, Chan E, et al. Nurses' knowledge of and compliance with universal precautions in an acutecare hospital. Int J Nurs Stud. 2002; 39: 157-63. http://dx.doi .org/10.1016/S 0020-7489 (01) 00021-9

[19] Gershon RR, Karkashian CD, Grosch JW. Hospital safety climate and its relationship with safe work practices and workplace exposure incidents. Am J Infect Control. 2000; 28(3): 211-21. PMid:10840340 http://dx.doi.org/10.1067/mic. 2000.105288

[20] Jeong I, Cho J, Park S. Compliance with standard precautions. among operating room nurses in South Korea. American Journal of Infection Control. 2008; 36: 739-742. PMid:18945523 http: //dx.doi.org/10.1016/j.ajic.2008.04.253

[21] Gordon GP. Research for practice: Practice behaviors of RNs related to hazardous risks with the clinical setting. Med Surg Nursing. 1999; 8(3): 174-177. PMid:10661152

[22] Kermode M, Jolley D, Langkham B, et al. Compliance with Universal/Standard Precautions among health care workers in rural north India. AJIC. 2005; 33(1): 27-33. http://dx. doi.org/10.1016 /j.ajic.2004.07.014

[23] El-Zanaty F, Way A. Egypt Demographic and Health Survey 2008 Egyptian: Ministry of Health. 2009, Cairo: El-Zanaty and Associates, and Macro International.

[24] Elder A, Paterson C. Sharps injuries in UK health care: A review of injury rates, viral transmission and potential efficacy of safety devices. Occup Med (Lond). 2006; 56: 566-74. PMid:17065314 http://dx.doi.org/10.1093/occmed/kql122

[25] Beghdadli B, et al. Respect des "précautions standards" par le personnel infirmier d'un centre hospitalo-universitaire de l'ouest algérien ["Standard precautions" practices among nurses in a university hospital in Western Algeria]. Sante Publique. 2008; 20: 445-453. http://dx.doi.org/10.3917/spub.085.0445

[26] Pruss-Ustun A, Rapiti E, Hutin Y. Sharps injuries: global burden of disease from sharps injuries to health care workers. Geneva, World Health Organization. 2003.

[27] Ramos-Gomez F, et al. Accidental exposures to blood and body fluids among health care workers in dental teaching clinics: a prospective study. Journal of the American Dental Association. 1997; 128: 1253-1261. http://dx.doi.org/10.14219/jada.archi ve. 1997.0402

[28] The world health report. Reducing risks, promoting health life Geneva, World Health Organization, 2002.

[29] Oliveira AC, Cardoso CS, Mascarenhas D. Contact precautions in intensive care units: facilitating and inhibiting factors for professionals' adherence. Rev Esc Enferm USP. 2010; 44(1): 161165. PMid:20394234 http://dx.doi.org/10.1590/S0080-623 42010000100023

[30] Sax H, Perneger T, Hugonnet S, et al. Knowledge of standard and isolation precautions in a large teaching hospital. Infect Control Hosp Epidemiol. 2005; 26(3): 298-304. PMid:15796284 http: //dx.doi.org/10.1086/502543

[31] Stein AD, Makarawo TP, Ahmad MF. A survey of doctors' and nurses' knowledge, attitudes and compliance with infection control guidelines in Birmingham teaching hospitals. J Hosp Infect. 2003; 54(1): 68-73. http://dx.doi.org/10.1016/S0195-670 1 (03) $00074-4$

[32] Osborne S. Influences on compliance with standard precautions among operating room nurses. Am J Infect Control. 2003; 31(7): 415-423. PMid:14639439 http://dx.doi.org/10.1067/mic. 2 003.68

[33] Amoran O, Onwube O. Infection control and practice of standard precautions among healthcare workers in Northern Nigeria. Journal of Global Infectious Diseases. 2013; 5: 156-163. PMid:24672178 http://dx.doi.org/10.4103/0974-777X.122010

[34] Oliveria AC, et al. Knowledge and attitude regarding standard precautions in a Brazilian public emergency service: a cross sectional study. Revista da Escola de Enfermagem da USP. 2009; 43(2): 313-319. http://dx.doi.org/10.1590/S0080-62342009000200009

[35] Lopez C, et al. Standard precautions: are these known? Are 18. they applied? Revista de Enfermeria (Barcelona, Spain). 2006; 29: 16-20. PMid:16493853

[36] Centers for Disease Control and Prevention. Workbook for designing, implementing and evaluating a sharps injury prevention program. 
2004. Available from: http://www.cdc.gov/sharpssafety/p df/WorkbookComplete.pdf

[37] Hashmi A, Abu Al Reesh S, Indah L. Prevalence of Needle-stick and Sharps Injuries among Healthcare Workers, Najran, Saudi Arabia. Epidemiol. 2012. http://dx.doi .org/10.4172/2161-116 5.1000117

[38] Singru S, Banerjee A. Occupational Exposure to Blood and Body Fluids Among Health Care Workers in a Teaching Hospital in Mumbai, India . Indian Journal of Community Medicine. 2008; 33(1): 2630. PMid:19966992 http://dx.doi.org/10.4103/0970-0218. 39239
[39] Siegel JD, Rhinehart E, Jackson M, et al. Guideline for Isolation Precautions:Preventing Transmission of Infectious Agents in Healthcare Settings. Healthcare Infection Control Practices Advisory Committee. 2007.

[40] Luo Y, He G, Zhou J, et al. Factors impacting compliance with standard precautions in nursing, China. International Journal of Infectious Diseases. 2010; 14: e1106-e1114. PMid:21071254 http: //dx.doi.org/10.1016/j.ijid.2009.03.037

[41] Clement A, Emma R, Johnson A. Survey of the knowledge, attitude and practice of Nigerian surgery trainees to HIV-infected persons and AIDS patients. BMC Surgery. 2002; 2: 7. http: //dx.doi.org/10.1186/1471-2482-2-7 